\title{
Comparative Study on Soil Microbial Biomass in Tarai and Hill Sal (Shorea robusta Gaertn.) Forests of Tropical Region in Eastern Nepal
}

\author{
Krishna Prasad Bhattarai ${ }^{1^{*}}$ and Tej Narayan Mandal ${ }^{2}$ \\ ${ }^{1}$ Department of Botany, Mechi Multiple Campus, TU, Bhadrapur, Nepal \\ ${ }^{2}$ Department of Botany, Post Graduate Campus, TU, Biratnagar, Nepal \\ *Corresponding Author \\ krishnaprbhattarai@gmail.com
}

\begin{abstract}
A comparative study was conducted to investigate the effect of altitudinal variation and seasonality on soil microbial biomass carbon (MB-C), nitrogen (MB-N), and phosphorus (MB-P) betweenTarai Sal forest (TSF) and Hill Sal forest (HSF) of the tropical region in eastern Nepal. Soil microbial biomass was estimated by chloroform fumigation - extraction method in summer, rainy and winter seasons in the upper $(0-15 \mathrm{~cm})$ soil depth in both forests. Pre-conditioned soil samples were saturated with purified liquid chloroform, represented fumigated sample. Another set of soil samples without using chloroform, represented unfumigated samples and soil microbial biomass was estimated from these samples. MB-C, MB-N, and MB-P were higher by $66 \%, 31 \%$, and $9 \%$, respectively, in HSF than TSF. Distinct seasonality was observed in soil microbial biomass. It was maximum in summer and minimum in rainy season in both the forest stands. The value decreased from summer to rainy season by 46 to $67 \%$ in HSF and by 32 to $80 \%$ in TSF. Higher soil microbial biomass in the summer season may be due to its accumulation in soil when the plant growth and nutrient demand are minimal. Analysis of variance suggested that $\mathrm{MB}-\mathrm{C}, \mathrm{MB}-\mathrm{N}$, and MB-P were significantly different for both sites and seasons $(\mathrm{P}<0.001)$. Soil organic carbon, TN, and TP were positively correlated with MB-C, MB-N, and MB-P in both the forests. In conclusion, the higher value of soil microbial biomass in HSF may be due to the higher concentration of soil organic matter and decreasing turnover rate of microbial biomass due to higher altitude. On the other hand, the lower value of microbial biomass at TSF may indicate its fast turnover rate due to lowland tropics to enhance the nutrient cycling process.
\end{abstract}

\section{Keywords}

Deciduous vegetation, microbial biomass, sal forest, seasonality, soil organic matter

\section{Introduction}

Soil microbial biomass is an active and living fraction of soil organic matter. It is a source and sink of available nutrients and plays a crucial role in nutrient exchange and conservation in forest ecosystems (Singh et al., 1989). Bacteria, fungi, actinomycetes, rotifers, and protozoa (up to $5 \times 10^{3} \mu \mathrm{m}^{3}$ size) are the major soil organisms that constitute the soil microbial biomass (Jenkinson and Ladd 1981). Though, it represents a small portion of soil organic matter, it is an active part due to its rapid turnover rate and fast release of available nutrients into the soil. Thus, it contributes to the nutrient cycle process far greater than its size (Schnurer et. al., 1985). The microbial activity also has a direct influence on ecosystem fertility and stability (Smith et al., 1993). Furthermore, microbial biomass acts as an essential ecological indicator that shows a quick response to any change in the ecosystem (Powlson and Jenkinson 1981). Microbial action is responsible for decomposition and mineralization of plant and animal residues in soil and thus helps to link the soil-plant nutrient cycling (Duffkova and Macurova 2011).

Variation in altitude is the main ecological factor that creates change in climatic conditions 
and so also in soil properties by affecting physical, chemical, and biological processes (Hutchins et al., 1976). Similarly, it also influences plant distribution, morphology, physiology, and plant growth (Li pan et al., 2009). With a rise in altitude, soil temperature decreases, which in turn leads to a reduction in microbiological activity. Therefore, carbon has longer retention time in the soil, and nitrogen levels are higher due to limited mineralization (Prichard et al., 2000). Soil microbes and their activities are also influenced by forest types, which mainly based on the quantity and quality of organic matter inputs. Besides this, seasonal variations in temperature, rainfall, and organic matter accumulation from litter fall also have a significant influence on soil microbial biomass (Chang et al., 2016).

Tarai Sal forests of Jalthal is a unique tropical forest of Nepal (Chaudhary et al., 2015). It has dense vegetation representing the components of deciduous forest and harbors many tropical, sub-tropical, as well as endangered species. On the other hand, Hill Sal forest located in the subHimalayan tract (Shiwaliks) represents a fragile ecosystem with a weak landscape. This forest contains upper tropical deciduous and semideciduous vegetation. Nowadays, these forests are disturbed by overgrazing, firewood collection, litter collection, timber cutting, and forest fire due to human settlements near the vicinities. Hill Sal forest has also been subjected to many natural disturbances, including landslide due to high altitude, weak lithology, and steep slopes (Bhatt 1977). Anthropogenic disturbance in the forest results in significant alternation in the microbial community and its activities (Srivastava and Singh 1989) and also in soil-microbe-plantnutrient cycling (Jordan 1985).

Sufficient information is not available on the status of soil microbial biomass in the forests having a distinct topographic variation. In the present work, an attempt has been made to evaluate the effect of the altitudinal change on the status of soil microbial biomass in Sal forests located in Tarai and Hill regions of the tropical belt in eastern Nepal. The work was designed to answer the following questions (i) What is the status of soil organic carbon, total nitrogen, and total phosphorus in these forests differing in altitude? (ii) How do soil microbial biomass carbon, nitrogen, and phosphorus vary in these forests? (iii) How does soil microbial biomass correlate with soil organic carbon, total nitrogen, and phosphorus and (iv) How seasonality effect on soil microbial biomass along the altitudinal gradient.

\section{Methodology}

\section{Study area}

The study was carried out in the Sal forests located in the Tarai and Hill regions of eastern Nepal. Sal forest of the Tarai region is addressed as Tarai Sal forest (TSF), which is situated at Jalthal near Kechana (Extreme low land of Nepal) of the Jhapa district. It occupies an area of 6300 ha, and altitudinal variation ranges from 62 to $129 \mathrm{~m} \mathrm{msl}$. The studied TSF is situated in between $87^{\circ} 55^{\prime}$ and $88^{\circ} 03^{\prime} \mathrm{E}$ and $26^{\circ} 27^{\prime}$ and $26^{\circ} 32^{\prime} \mathrm{N}$ (Fig. 1). Sal forest of Hill region is addressed as Hill Sal forest (HSF), which is located at Kiteni of Kolbung, Ilam district. This forest lies at the sub-Himalayan tract (Shiwaliks), where the altitude ranges from 500 to $850 \mathrm{~m} \mathrm{msl}$. The studied HSF is situated in between $88^{\circ} 02^{\prime}$ and $88^{\circ} 04^{\prime} \mathrm{E}$ longitude and $26^{\circ} 44^{\prime}$ and $26^{\circ} 47^{\prime} \mathrm{N}$ latitude.

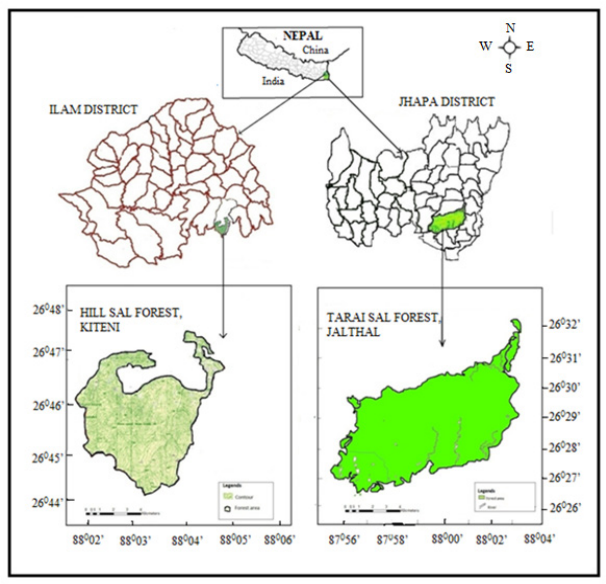

Fig. 1. Location of study area of Hill Sal forest at Kiteni, Ilam district, and Tarai Sal forest at Jalthal, Jhapa district in eastern Nepal.

\section{Climate}

The climate of the study area is tropical monsoon type. Based on the data about the period 20012014, the mean monthly minimum temperature 
ranged from $10.05^{\circ} \mathrm{C}$ to $23.99^{\circ} \mathrm{C}$, and maximum temperature ranged from $23.92^{\circ} \mathrm{C}$ to $33.45^{\circ} \mathrm{C}$ in the TSF (Fig. 2a). Likewise, the mean monthly minimum temperature of $\mathrm{HSF}$ ranged from $9.36^{\circ} \mathrm{C}$ to $19.88^{\circ} \mathrm{C}$, while the maximum temperature ranged from $16.45^{\circ} \mathrm{C}$ to $25.91^{\circ} \mathrm{C}$ (Fig. 2b). The average annual rainfall of TSF was $2130.4 \mathrm{~mm}$, and HSF was $1776.07 \mathrm{~mm}$ (Fig. 2a \& 2b). Data on temperature and precipitation were recorded at Kankai Irrigation Base Camp Observatory, Gaida, Jhapa (90 m msl), and Ilam Base Camp Observatory, Ilam Bazar, Ilam (1200 m msl).

\section{Soil sampling and analysis}

Each forest stands of TSF and HSF was demarcated in the outer buffer area and inner core area. The inner core area considered as the sampling area was divided into 100 compartments. As per the

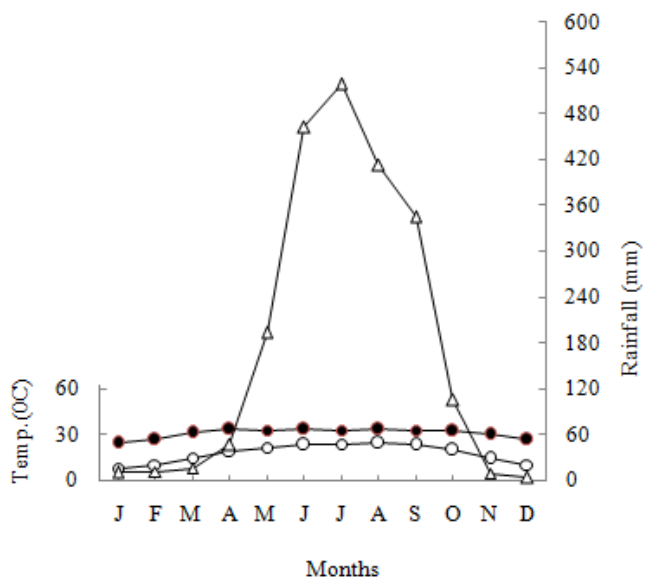

(2a)
Physico-chemical properties were estimated in both depths. Soil microbial biomass carbon, nitrogen, and phosphorus were determined in the upper depth $(0-15 \mathrm{~cm})$ for each season.

Air-dried soil samples were sieved through a $2 \mathrm{~mm}$ mesh screen and used for further analysis. Soil texture was estimated by the sieve method. Water holding capacity (WHC) was assessed by a perforated circular brass box method (Piper 1966). Bulk density (BD) was determined by inserting metallic tubes of known internal volume in soil and, after that, estimating the dry weight of a unit volume of soil (Brady and Weil 2013). Soil moisture was determined by the ovendry method and soil temperature measured by soil thermometer. Soil $\mathrm{pH}$ was measured by using a glass electrode (1:5, soil: water). Soil

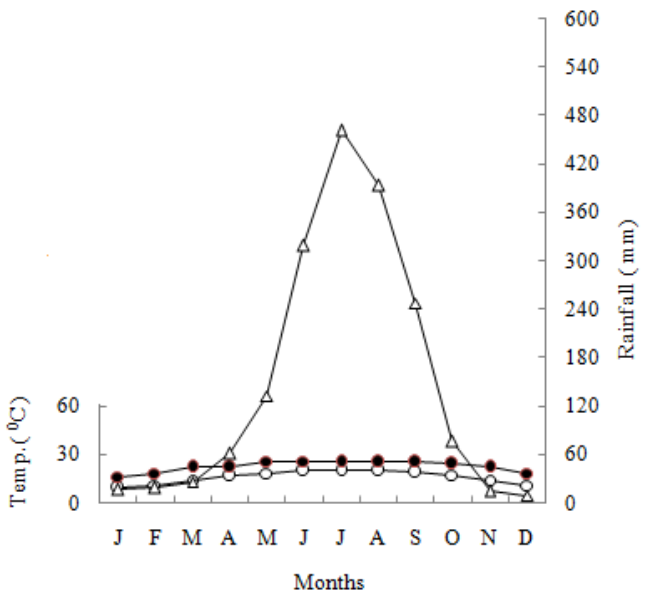

(2b)

Fig. 2. Ombrothermic representation of the climate inTarai Sal forest (2a) and Hill Sal forest (2b) regions of Nepal. The temperature ( $\bullet$; mean monthly minimum and $\bullet-$; mean monthly maximum) and $₫$; rainfall data pertain to the period 2001-2014(Source: Department of Hydrology and Meteorology, Government of Nepal)

partial random sampling, 30 compartments were selected randomly. Within each compartment, $20 \mathrm{~m} \times 20 \mathrm{~m}$ permanent plot was fixed randomly for sampling. Soil samples were collected in two soil depths $(0-15 \mathrm{~cm}$ and $15-30 \mathrm{~cm})$ from thirty randomly selected plots in each forest site. At each plot, the soil was collected from three pits $(10 \mathrm{~cm} \times$ $10 \mathrm{~cm} \times 15 \mathrm{~cm}$ ), mixed and pooled as one replicate. Such type of thirty replicates was taken for soil analysis. Soil sampling was carried out in May, July and January (2012 and 2013) representing the summer, rainy, and winter season, respectively. organic carbon was analyzed by using potassium dichromate and digestion of soil samples with $\mathrm{H}_{2} \mathrm{SO}_{4}$ and titration with ferrous sulfate (Walkley and Black 1934). Total nitrogen was estimated by the micro-Kjeldahl method (Jackson 1958). Total phosphorus was determined calorimetrically by ammonium molybdate-stannous chloride blue color method after digesting the soil in a tri-acid mixture of $\mathrm{HClO}_{4}, \mathrm{HNO}_{3}$, and $\mathrm{H}_{2} \mathrm{SO}_{4}$ in the ratio of 1:5:1 (Jackson 1958). Potassium was estimated by atomic absorption spectrophotometer. 


\section{Determination of soil microbial biomass}

Soil microbial biomass was estimated by the chloroform fumigation extraction method. Microbial biomass carbon (MB-C) was determined in the $\mathrm{K}_{2} \mathrm{SO}_{4}$ soil extract of fumigated and unfumigated soil samples by dichromate oxidation in a reflux system and titration with ferrous ammonium sulfate. Microbial biomass carbon was then estimated from the equation: $\mathrm{MB}-\mathrm{C}=2.64 \mathrm{E}_{\mathrm{c}}$ where $\mathrm{E}_{\mathrm{c}}$ is the difference between carbon calculated from fumigated and unfumigated soils, both expressed as $\mathrm{C} \mu \mathrm{g} \mathrm{g}^{-1}$ dry soil (Vance et al., 1987). Soil microbial biomass nitrogen (MB-N) was determined in the same soil extract of fumigated and unfumigated soil samples using the Kjeldahl digestion method. The MB-N value obtained for the unfumigated soil extract was subtracted from the value derived from that of fumigated soil extract; the difference in the amount of total nitrogen thus estimated was divided by a $\mathrm{K}_{\mathrm{N}}$ value of 0.54 assuming that $54 \%$ of the MB-N was extracted in $\mathrm{K}_{2} \mathrm{SO}_{4}$ by chloroform treatment (Brookes et al., 1985).

Soil microbial biomass phosphorus (MBP) was estimated in the $\mathrm{NaHCO}_{3}$ extracts of fumigated and unfumigated soils using the ammonium molybdate stannous chloride method. Microbial biomass phosphorus was calculated by dividing the value obtained as inorganic phosphorus $(\mathrm{P})$ by a $\mathrm{K}_{\mathrm{P}}$ value of $0.4\left(\mathrm{NaHCO}_{3}\right.$ inorganic $\mathrm{P}$ in fumigated subtracted from that of unfumigated), assuming that $40 \%$ of $\mathrm{P}$ in the soil microbial biomass is released as inorganic $\mathrm{P}$ by chloroform treatment. A correction was made for $\mathrm{P}$ fixation during the $\mathrm{NaHCO}_{3}$ extraction by measuring the recovery of exogenously added inorganic $\mathrm{P}$ as $\mathrm{KH}_{2} \mathrm{PO}_{4}$ (equivalent to $20 \mu \mathrm{g} \mathrm{P} \mathrm{g}{ }^{-1}$ soil), as suggested by Brookes et al., (1982).

\section{Statistical analysis}

The data obtained from the analysis of soil samples were subjected to two-way ANOVA to test the level of significance and least significant difference (LSD) by applying post hoc to distinguish the differences in soil chemical properties between two Sal forests by using SPSS 20 statistics software. Correlation analysis was done in between soil organic carbon, total nitrogen, total phosphorus, potassium, microbial biomass carbon, microbial biomass nitrogen, and microbial biomass phosphorus from upper soil depth $(0-15 \mathrm{~cm})$ of TSF and HSF.

\section{Results}

Soil physico-chemical properties of TSF and HSF viz. texture, moisture, BD, WHC, $\mathrm{pH}, \mathrm{SOC}$, TN, TP, MB-C, MB-N, and MB-P are presented in Table 1 and Table 2. Both forests had sandy loam type of soil texture. The proportion of sand showed a marked increase with soil depth in both forests, but silt increased with depth only in TSF. Clay decreased along with the soil depth in TSF. Soil moisture of TSF was higher than HSF, and in both forest types, it was higher in the rainy season than winter and summer seasons. The $\mathrm{pH}$ value was slightly higher in HSF than TSF. However, the value increased in lower soil depth in both forest stands. The water holding capacity was marginally higher in TSF than HSF. It decreased with soil depth in both forests. Bulk density was higher in TSF than HSF and increased with soil depth. In the upper soil depth, soil organic carbon was higher in HSF $(2.09 \%)$ than TSF $(1.6 \%)$, and it decreased depth-wise. Total nitrogen was also higher in HSF $(0.173 \%)$ than in TSF $(0.129 \%)$, while total phosphorus was the same in both forest stands. The potassium, an extractable soil nutrient, also showed a higher value in $\operatorname{HSF}\left(312.13 \mu \mathrm{g} \mathrm{g}^{-1}\right)$ than TSF $\left(238.47 \mu \mathrm{g} \mathrm{g}^{-1}\right)$. The value of SOC, TN, $\mathrm{TP}$, and $\mathrm{K}$ decreased depth-wise in both forest stands (Table 1).

ANOVA suggested that the variation in MB-C, MB-N and MB-P were significantly different for sites (for $\mathrm{MB}-\mathrm{C}, \mathrm{F}_{1,174}=136, \mathrm{P}<0.001 ; \mathrm{MB}-\mathrm{N}$, $\mathrm{F}_{1,174}=39, \mathrm{P}<0.001$; MB-P, $\left.\mathrm{F}_{1,174}=86, \mathrm{P}<0.001\right)$ as well as for seasons (for MB-C, $\mathrm{F}_{2,174}=47, \mathrm{P}<$ 0.001; MB-N, $\mathrm{F}_{2,174}=57, \mathrm{P}<0.001 ; \mathrm{MB}-\mathrm{P}, \mathrm{F}_{2}$, $\left.{ }_{174}=696, \mathrm{P}<0.001\right)$.Adistinctseasonal variation was also observed in the content of MB-C, MB-N, and MB-P in both the sites. Minimum values were obtained in the rainy season and maximum in the summer season (Fig. 3). The annual mean value of MB-C, MB-N, and MB-P showed an increasing trend along with the increasing altitude. Hill Sal forest showed $66 \%, 31 \%$, and $9 \%$ higher value of MB-C, MB-N, and MB-P over TSF (Table 2), respectively. Microbial biomass carbon, nitrogen, and phosphorus reduced by $46 \%$ to $67 \%$ from 
summers to rainy in HSF. The rate of reduction from summer to rainy was even higher (32 to $80 \%$ ) in TSF. The ratios MB-C: MB-N, MB-C: MB-P, and MB-N: MB-P were higher in HSF than TSF (Table 2). Based on the annual mean value, MB-C, MB-N, and MB-P as a fraction of SOC, TN and TP were comparable between HSF and TSF except MB-C as a fraction of SOC which was higher in HSF (Table 3). Microbial biomass carbon, nitrogen, and phosphorus were positively and significantly correlated with SOC, TN and TP in both forests stands (Table 4 and 5).

\section{Discussion}

Variation in altitude within a short distance is a common phenomenon due to the widespread of mountains in the forest ecosystems of Southeast

Table 1. Soil characteristics of the Tarai Sal forest and Hill Sal forest of eastern Nepal. Values are means \pm 1 SE $(n=30)$.

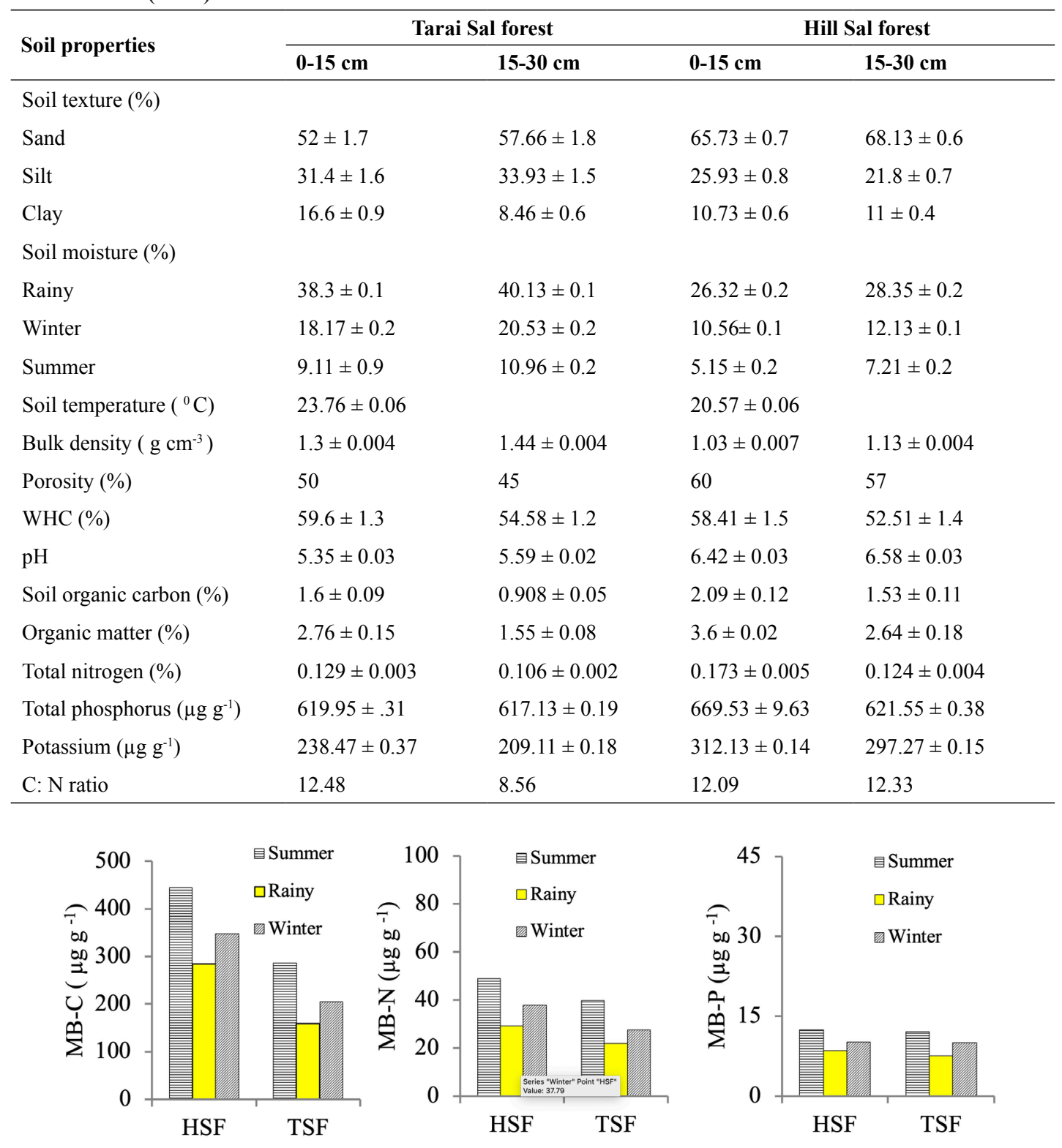

Fig. 3. Seasonal variation in MB-C, MB-N, and MB-P in Hill Sal forest and Tarai Sal forest of eastern Nepal. 
Nepal Journal of Science and Technology (NJST) (2020), 19(1)

Table 2. Soil microbial biomass (MB-C, MB-N, MB-P) and their ratio in TSF and HSF of eastern Nepal. Values are mean of summer, rainy, and winter seasons $(n=90)$.

\begin{tabular}{ccccccc}
\hline \multirow{2}{*}{ Forests } & \multicolumn{3}{l}{ Soil Microbial biomass $\left(\mu \mathrm{g} \mathrm{g}^{-1}\right)$} & & \\
\cline { 2 - 4 } Tarai Sal forest & MB-C & MB-N & MB-P & MB-C: MB-N & MB-C: MB-P & MB-N: MB-P \\
\cline { 2 - 5 } & 216.2 & 29.67 & 9.85 & 7.28 & 21.94 & 3.01 \\
Hill Sal forest & \pm 11.8 & \pm 1.35 & \pm 0.04 & & & \\
& 359.08 & 38.72 & 10.72 & 9.27 & 33.49 & 3.61 \\
& \pm 13.94 & \pm 1.62 & \pm 0.08 & & & \\
\hline
\end{tabular}

Table 3. Soil microbial biomass (MB-C, MB-N, MB-P) as a percentage of SOC, TN, and TP in the Tarai Sal forest and Hill Sal forest of eastern Nepal.

\begin{tabular}{cccc}
\hline \multirow{2}{*}{ Forests } & \multicolumn{3}{c}{ Soil microbial biomass as \% of } \\
\cline { 2 - 4 } & Soil organic carbon & Total nitrogen & Total phosphorus \\
\hline Tarai Sal forest & 1.3 & 2.3 & 1.5 \\
Hill Sal forest & 1.7 & 2.2 & 1.6 \\
\hline
\end{tabular}

Table 4. Correlation between soil microbial biomass and other soil chemical properties in TSF of eastern Nepal.

\begin{tabular}{ccccccc}
\hline & SOC & TN & TP & K & MB-C & MB-N \\
\cline { 2 - 6 } TN & $0.640^{* *}$ & & & & \\
TP & $0.493^{* *}$ & $0.683^{* *}$ & & & & \\
K & -0.037 & -0.213 & -0.251 & & \\
MB-C & $0.719^{* *}$ & $0.668^{* *}$ & $0.569^{* *}$ & -0.22 & & \\
MB-N & $0.678^{* *}$ & $0.761^{* *}$ & $0.437^{*}$ & -0.083 & $0.700^{* *}$ & \\
MB-P & $0.448^{*}$ & $0.549^{* *}$ & $0.562^{* *}$ & -0.155 & $0.536^{* *}$ & $0.577^{* *}$ \\
\hline
\end{tabular}

** Correlation is significant at the 0.01 level (2-tailed).

* Correlation is significant at the 0.05 level (2-tailed).

able 5. Correlation between soil microbial biomass and other soil chemical properties in HSF of eastern Nepal.

\begin{tabular}{ccccccc}
\hline & SOC & TN & TP & K & MB-C & MB-N \\
\cline { 2 - 6 } TN & $0.734^{* *}$ & & & & & \\
TP & -0.038 & -0.100 & & & & \\
K & $0.671^{* *}$ & $0.603^{* *}$ & -0.219 & & & \\
MB-C & $0.789^{* *}$ & $0.579^{* *}$ & 0.023 & $0.439^{*}$ & & \\
MB-N & $0.565^{* *}$ & $0.668^{* *}$ & 0.036 & 0.219 & $0.705^{* *}$ & \\
MB-P & 0.349 & $0.387^{*}$ & 0.053 & 0.072 & $0.373^{*}$ & $0.663^{* *}$ \\
\hline
\end{tabular}

T** Correlation is significant at the 0.01 level (2-tailed).

* Correlation is significant at the 0.05 level (2-tailed). 
Asia. This variation can influence the microclimate, such as the temperature and moisture (Chang et al., 2016). Finally, it changes the soil's physical, chemical, biological properties, including soil microbial biomass. In the present study, the soil texture in both the forests was sandy loam. The values of soil moisture and water holding capacity were higher in the Tarai Sal forest which might be due to the presence of a relatively higher amount of clay, giving them the exceptional ability to adsorbed water and other substances (Brady and Weil 2013).

Moreover, TSF showed higher soil temperature and moisture than HSF, which may enhance the decomposition of litter and fine root turnover rate; as a result, the soil might be enriched with available nutrients causing higher water holding capacity (Reth et al., 2005). The bulk density in $0-15 \mathrm{~cm}$ depth was higher in TSF than HSF and increased in lower depth in both Sal forests. The relatively lower value of bulk density in HSF might be due to the presence of higher organic matter accumulation in the soil than the TSF. Tarai Sal forest contained acidic soil than Hill Sal forest, and acidic nature decreased along with soil depth in both the forests.

Tarai Sal forest had a lower value of soil organic carbon and total nitrogen, which increased along with higher altitude. At the lower elevated landscape of TSF, higher soil moisture and temperature cause a fast turnover of litter and fine root due to which there may be less accumulation of organic matter. On the other hand, higher accumulation of soil organic carbon and total nitrogen at Hill Sal forest may be due to low soil temperature and moisture, causing reduced decomposition and slow turnover of organic matter. The same trend relating to altitude, temperature, and decomposition has also been reported by Griffiths et al., 2009. Tsui et al., (2013) also found a positive relationship between elevation and soil organic matter.

Similarly, DFRS (2015) also showed that SOC stock in the forest was found to increase with increasing altitude. The total nitrogen of the Hill Sal forest was higher than the Tarai Sal forest. A similar trend was also reported by Li et al., (2013) in the Gongga mountain of western China. Lower temperature due to high altitude in the Hill Sal forest may cause the slow rate of mineralization and nitrogen turnover; thus, accumulation occurs at a high rate. Moreover, there is a longer residence time of nitrogen in the litter and a decrease in soil nitrogen losses at a higher altitude than lower altitude (Smith et al., 2002).

Soil microbial biomass is the primary source of nutrients for the plant (Singh et al., 1989). They regulate the decomposition of plant litter, increase the level of available nutrients and rate of N-mineralization. The status and activities of microbial biomass are generally influenced by altitude (Chang et al., 2016), vegetation types and quality as well as quantity of plant litter (Hackl et al., 2004; Jin et al., 2010). In the present study, soil microbial biomass carbon, nitrogen, and phosphorus in the low elevated stand were lower than in high elevated, i.e., it was found higher in HSF. This finding might be attributed to the decreasing of microorganism turn over rate at high altitude. The relatively lower microbial turn over rate in Hill Sal forest is evident from the higher microbial C:N:P ratio in HSF $(33: 5: 1)$ than the TSF (22:3:1). This variation is mainly due to differences in altitudinal topography, which influences the environmental conditions and alters air temperature, atmospheric humidity, and soil moisture (Scowcroft et al., 2000). An increase in the size of microbial biomass is linked with a widening of MB-C: MB-N ratio from TSF to HSF. It suggests that the topographic variation alters both the size and composition of microbial biomass.

Furthermore, soil microbial biomass and its activities are dependent on the quality, quantity, and decomposing organic matter present in the forest floor (Barbhuiya et al., 2008). Hill Sal forest had a higher value of organic matter than the Tarai Sal forest, and so also soil microbial biomass carbon, nitrogen, and phosphorus were high. It is evident from the significant positive correlation of MB-C, MB-N, and MB-P with soil organic matter. Chang et al., (2016) and Chen et al., (2005) also reported that the soil microbial biomass is highly correlated with soil organic matter. Relatively higher accumulation of litter and fine root favor the growth of microorganisms and the collection of carbon, nitrogen, and phosphorus in the microbial biomass. Microbial composition and activity also 
depend upon nutrient availability of soil as there is a positive correlation between MB-C, MB-N, and MB-P with SOC, TN, and TP in both forests (Couteaux et al., 1998).

Soil microbial biomass carbon, nitrogen, and phosphorus showed distinct seasonal variation in both forest stands. The maximum value of soil microbial biomass during the summer season might be due to its accumulation when plant growth and nutrient demand are minimal. On the other hand, the value of soil microbial biomass was minimum during the rainy season because of the fast turn over of microorganisms and optimum utilization of nutrients by the plants when growth and development remain at the peak. A similar trend of seasonal variation was observed by Singh et al., (2001) in a moist tropical Sal forest located at Panchakanyaplateau of Sunsari district, eastern Nepal. Arunachalam and Arunachalam (2000) in the humid subtropical forest of Northeast India, Singh et al., (2010) in the tropical forest of Vindhyan Plateau India and Tripathi and Singh (2012) in Indian tropical forest have also reported same trends regarding the effects of seasonality on soil microbial biomass. The low value of soil MB-C, MB-N, and MB-P during the rainy season might also be due to sudden change in environmental conditions (drying, rewetting, and soil temperature fluctuations) that cause the death of a large amount of the microbial biomass (Singh et al., 2010). The death of the microbes and release of microbial nutrients at the start of the rainy season supports the initiation of plant growth.

\section{Conclusion}

Hill Sal forest influences the environmental conditions due to having high altitude. As a result, may have an impact on accumulation, decomposition, and turnover of organic matter. It has a higher value of soil organic matter than the Tarai Sal forest, and so also soil microbial biomass carbon, nitrogen, and phosphorus are higher. Soil microbial biomass carbon, nitrogen, and phosphorus also showed distinct seasonal variation in both forest stands. It was maximum in summer season due to its accumulation in soil when the plant growth and nutrient demand are minimum, and minimum in the rainy season which may be due to high turnover of microbial biomass and proper utilization of converted nutrients in a situation when growth and development of the plants lie at the peak.

\section{Acknowledgments}

The authors are grateful to the Head, Department of Botany, and to the Campus Chief of Post Graduate Campus, TU, Biratnagar, Nepal, for providing laboratory and library facilities. The first author is grateful to the Institute of Science and Technology Tribhuvan University Kathmandu for Ph. D. study leave and to the University Grants Commission, Nepal, for the research fellowship.

\section{References}

Arunachalam, A., and K. Arunachalam, 2000. Influence of gap size and soil properties on microbial biomass in humid subtropical forest of north-east India.Plant and Soil 223: 185-193.

Barbhuiya, A.R., A. Arunachalam, H.N. Pandey, M.L. Khani, and K. Arunachalam, 2008. Effects of disturbance on fine roots and soil microbial biomass $\mathrm{C}, \mathrm{N}$, and $\mathrm{P}$ in a tropical rainforest ecosystem of Northeast India.Current Science 94: $572-574$.

Bhatta, D.D., 1977. Natural History and Economic Botany of Nepal. Orient Longman Limited.

Brady, N.C., and R. Weil, 2013.The nature and properties of soils.Pearson Education.

Brookes, P.C., A. Landman, G. Prudenand D.S. Jenkinson 1985. Chloroform fumigation and the release of soil nitrogen: A rapid direct extraction method to measure microbial biomass nitrogen in the soil. Soil Biology \& Biochemistry 17: 837-842.

Brookes, P.C., D.S. Powlson, and D.S. Jekinson 1982. Measurement of microbial biomass phosphorus in soil.Soil Biology \& Biochemistry 14, 391-329.

Burns, S.F., and P.J. Tonkin1982.Soilgeomorphic models and the spatial distribution and development of alpine soils. In: Thorne, C.E. (ed.), Space and Time in Geomorphology.Allen \& Unwin, London, UK, 25-43.

Chang, E.-H., T.-H. Chen, G. Tianand and C.-Y. Chiu 2016. The effect of altitudinal gradient on soil microbial community activity and structure in moso bamboo plantations. Applied Soil Ecology 98: $213-220$.

Chaudhary, R.P., Y. Uprety, S.P. Joshi, K.K. Shrestha, K.B. Basnet, G.Basnet, K.R. Shrestha, K.P. Bhatta, 
K.P. Acharya, and N. Chettri 2015. Kangchenjunga Landscape Nepal: from conservation and development perspectives. Ministry of Forests and Soil Conservation (MoFSC), Government of Nepal; ResearchCentre for Applied Science and Technology (RECAST), Tribhuvan University; and International Centre for Integrated Mountain Development (ICIMOD). Kathmandu, Nepal.

Chen, C.L., M. Liao, and CY. Huang 2005. Effect of combined pollution by heavy metals on soil enzymatic activities in areas polluted by tailing from $\mathrm{Pb}-\mathrm{Zn}-\mathrm{Ag}$ mine. Journal of Environmental Sciences 17: 637-640.

Couteaux, M., M. Raubuch, and M. Berg, 1998. The response of protozoan and microbial communities in various coniferous forest soils after transfer to forests with different levels of atmospheric pollution. Biology \& Fertility of Soils 27: 179 -188 .

DFRS, 2015.State of Nepal's Forests. Forest Resource Assessment (FRA) Nepal, Department of Forest Research and Survey (DFRS). Kathmandu, Nepal.

Duffkova, R., and H. Macurova, 2011.Soil biological quantity and quality parameters of grasslands in various landscape zones.Plant Soil Environment 57: 577-582.

Griffiths, R.P., M.D. Madritchand A.K. Swanson,2009. The effects of topography on forest soil characteristics in the Oregon Cascade Mountains (USA): Implications for the impact of climate change on soil properties. Forest Ecology and Management 257(1): 1-7.

Hackl, E., G. Bachmann, and S. ZechmeisterBoltenstern 2004. Microbial nitrogen turnover in soils under different types of natural forest. Forest Ecology \& Management 188:101-12

Hutchins, R.L., JD Hill, and E.H. White. 1976. The influence of soil and microclimate on the vegetation of forested slopes in eastern Kentucky. Soil Science 121: 234-241.

Jakson, M.L., 1958. Soil Chemical Analysis. Prentice Hall, Inc., Engle Wood Cliffs, New Jersey.

Jenkinson, D.S., and J.N. Ladd, 1981. Microbial biomass in soil: measurement and turnover. Soil Biochemistry vol. 5 (eds E.A. Paul \& J.N. Ladd), Marcel Dekker, New York. 415-471.

Jin, H., OJ. Sun and J. Liu, 2010. Changes in soil microbial biomass and community structure with the addition of different types of plant litter in a semiarid grassland ecosystem. Journal of Plant Ecology 3: 209-217.
Jordan, C.F., 1985. Nutrient Cycling in Tropical Forest Ecosystems; Principles and their Application in Management and Conservation. John Wiley \& Sons, Chichester, England.

Li Pan, H., X.L. Liu, X.H. Cai, Z. Du, F. He, L. Wang, C. Jia, and M.H. Li, 2009. Growth and morphological responses of Fargesiaangustissima to altitude in the Wolong nature reserve, southwestern China. Acta EcologicaSinica 29: 144-149.

Li, W., G. Yang, H. Chen, J. Tian, Y. Zhang, Q. Zhu, C. Pengand J. Yang, 2013. Soil available nitrogen, dissolved organic carbon, and microbial biomass content along an altitudinal gradient of the eastern slope of Gongga Mountain. Acta Ecologica Sinica 33(5), 266-271.

Piper, C.S. 1966.Soil and Plant Analysis. Hans Publisher, Bombay.

Powlsson, D.S., and D.S. Jenkinson, 1981. A comparison of organic matter, biomass, adenosine triphosphate, and mineralizable nitrogen contents of ploughed and direct-drilled soils. Journal of Agricultural Science 97: 713-721.

Prichard, S.J., D.L. Peterson and R.D. Hammer, 2000. Carbon distribution in subalpine forests and meadows of the Olympic Mountains, Washington. Soil Science Society of America Journal 64(5): 1834-1845.

Reth, S., M. Reichstein, and E. Falge, 2005. The effect of soil water content, soil temperature, soil pHvalue, and the root mass on soil $\mathrm{CO}_{2}$ efflux: $\mathrm{A}$ modified model. Soil Plant 268: 21-23.

Scowcroft, P.G., D.R. Turner, and P.M. Vitousek 2000. Decomposition of Metrosiderospolymorpha leaf litter along elevational gradients in Hawaii. Global Change Biology 6: 73-85.

Shnürer, J., M. Clarholm, and T. Rosswall, 1985. Microbial Biomass and activity in agricultural soil with different organic matter contents. Soil Biology \& Biochemistry 17: 611-618.

Singh, J.S., A.S. Raghubanshi, R.S. Singh, and SC. Srivastava, 1989. Microbial Biomass acts as a source of plant nutrients in dry tropical forests and savanna. Nature 338: 499-500.

Singh, J.S., D.P. Singh, and A.K. Kashyap, 2010. Microbial biomass $\mathrm{C}, \mathrm{N}$, and $\mathrm{P}$ in disturbed dry tropical forest soils, India. Pedosphere 20: 780-788.

Singh, K.P., T.N. Mandal, and S.K.Tripathi 2001. Patterns of restoration of soil physicochemical properties and microbial biomass in different 
landslide sites in the Sal forest ecosystem of Nepal Himalaya. Ecological Engineering 17: 385-401.

Smith, J.L., J.J. Halvorson, and H.B. Jr, 2002. Soil properties and microbial activity across a $500 \mathrm{~m}$ elevation gradient in a semiarid environment. Soil Biology and Biochemistry 34: 1749-1757.

Smith, J.L., R.I.Papendick,,D.F. Bezdicek,J.M. Lynch, 1993. Soil organic matter dynamics and crop residue management. In: Metting, Blaine (Ed.), Soil Microbial Ecology. Marcel Dekker, New York, pp. 65-95.

Srivastava, S.C. and J.S.Singh, 1989. Effect of cultivation on microbial carbon and nitrogen in dry tropical forest soil.Biology \& Fertility of Soil 8: 343-348.

Tripathi, N. and R.S. Singh, 2012.Impact of
Savannization on Nitrogen Mineralization in an Indian Tropical Forest.Forest Resources 1:108115.

Tsui, C.C., C.C. Tsaiand Z.S. Chen, 2013. Soil organic carbon stocks in relation to elevation gradients in volcanic ash soils of Taiwan. Geoderma 209: 119-127.

Vance, E.D., PC. Brookes and D.S. Jenkinson, 1987. Microbial biomass measurement in forest soils: The use of the chloroform fumigation-incubation method in strongly acid soils. Soil Biology \& Biochemistry 19: 697-702.

Walkey, A.E., and J.D. Black, 1934. An examination of the Degtiga Vett. Method for determining soil organic matter and proposed modification of the chromic acid titration method.Soil Science 37: 2. 